\title{
El Sistema Político Venezolano en el periodo 1999-2020: ¿persistencia o ruptura?
}

\section{Venezuelan political system in the period 1999-2020: persistence or breach}

\author{
Rosangel Mariela Álvarez Itriago \\ Universidad Simón Bolívar, Venezuela \\ rosalvarez@usb.ve
}

\begin{abstract}
Resumen
En este artículo se examinan los cambios que han ocurrido en el Sistema Político Venezolano durante el periodo 19992020, bajo la presidencia de Hugo Chávez y de su sucesor, Nicolás Maduro, a partir del enfoque analítico propuesto por David Easton (1999), y se intenta comprender hasta dónde el socialismo del siglo XXI, proyecto politico impulsado en dicho periodo, anclado en el liderazgo personal, la convocatoria a una amplia movilización popular y la proclamación de una nueva institucionalidad, introduce una serie de tensiones que tienden a amenazar la persistencia del sistema democrático. A partir de una investigación histórico-documental de carácter descriptivo, se concluye que la primacía del Poder Ejecutivo sobre el resto de los poderes públicos y la utilización de recursos no democráticos evidencian elementos de regresión autoritaria en el país.
\end{abstract}

Palabras clave: autoritarismo, democracia, sistema político, Venezuela.

\begin{abstract}
This article examines the changes that have occurred in the Venezuelan Political System during the period 1999-2020, under the presidency of Hugo Chávez and his successor, Nicolás Maduro, based on the analytical approach proposed by David Easton (1999), and it is tried to understand up to where the Socialism of the XXI Century, a political project promoted in that period, anchored in personal leadership, the call for a broad popular mobilization and the proclamation of a new institutionality, introduces a series of tensions that tend to threaten the persistence of the democratic system. From a descriptive historical-documentary research, it is concluded that the primacy of the Executive Power over the rest of the public powers and the use of non-democratic resources show elements of authoritarian regression in the country.
\end{abstract}

Keywords: Authoritarianism, Democracy, Political System, Venezuela.

Articulo: Recibido el 30 de junio de 2021 y aprobado el 13 de octubre de 2021

\section{Cómo citar este artículo:}

Álvarez Itriago, R.M. (2021). El Sistema Político Venezolano en el período 1999-2020: ¿persistencia o ruptura? Reflexión politica 23(48), pp. 81-96. doi: https://doi.org/10.29375/01240781.4188

\section{Introducción}

En Venezuela, la crisis del sistema de conciliación de élites políticas establecido a partir de 1958 con la instalación de la democracia, afectó la legitimidad de los partidos políticos (Molina, 2001) y produjo cambios importantes en la dirigencia política del país cuando fue elegido Hugo Chávez como presidente de la república en 1998. La naturaleza de esta crisis, así como su impacto hacia el Sistema Político Venezolano, ha dado lugar a diversas lecturas e interpretaciones por parte de los estudiosos del tema para tratar de comprender y explicar cómo la democracia venezolana, considerada excepcional con respecto al resto de la región (Levine, 1994), se sumergió en una severa crisis que se evidenció a partir de 1989, 
mostrando en la actualidad signos de profundización y erosión de las condiciones mínimas para el juego democrático.

En este escenario, en el presente artículo se examina el Sistema Político Venezolano durante el período 1999-2020, bajo la presidencia de Hugo Chávez y su sucesor, Nicolás Maduro, a partir del enfoque analítico propuesto por David Easton (1999). El objetivo es comprender hasta qué punto la propuesta política del socialismo del siglo XXI aplicada en dichos gobiernos, anclada en el liderazgo personal, la convocatoria a una amplia movilización popular y la proclamación de una nueva institucionalidad, introducen una serie de tensiones que tienden a amenazar la persistencia del sistema democrático, evidenciándose elementos de una regresión autoritaria ${ }^{1}$ en el país.

A los fines de aproximarnos a esta problemática, la discusión se organiza en tres apartados. En la primera parte, se esboza el enfoque analítico sistémico propuesto por David Easton para estudiar los sistemas políticos, precisando las categorías analíticas para abordar el estudio del caso venezolano. En segundo lugar, se caracteriza el Sistema Político Venezolano durante el período que precedió al ascenso de Hugo Chávez al poder, esto es, desde 1958 hasta 1998, destacando los aspectos más importantes que permiten comprender la denominada crisis del sistema.

El tercer apartado de desarrolla en dos partes: en la primera parte, se esbozan los principales rasgos que caracterizan al Sistema Político Venezolano bajo la presidencia de Hugo Chávez (1999-2013) y, en la segunda parte, se identifican los principales elementos que aporta la gestión gubernamental de Nicolás Maduro (2013-Actualidad) a dicho sistema, en función de la teoría de Easton. Para cerrar, se plantean algunas consideraciones finales.

\section{Estudio de los sistemas politicos: el enfoque de David Easton}

Existen diversos enfoques teóricos para estudiar los sistemas políticos. Estos enfoques abarcan las teorías conductistas, el enfoque estructural-funcionalista, la teoría de la acción, la teoría de la elección racional, entre otras. Pero la que ha tenido mayor impacto en el análisis político ha sido el enfoque sistémico (Marsh y Stoker, 2010). Siendo la vertiente sistémica en la teoría política una de las opciones analíticas más importantes, se adoptó dentro de esta vertiente el enfoque propuesto por David Easton (1999), quien propone una serie de categorías de relevancia teórica para estudiar los sistemas políticos como sistemas de conductas que obedecen a condiciones históricas y de retroalimentación que explican su estado actual.

Para el estudio del caso venezolano, Easton nos ofrece un enfoque que permite describir los procesos de cambio que están afectando este sistema político, inscritos en una propuesta "revolucionaria" y "socialista" por parte del gobierno nacional que introduce parámetros que podrían derivar en situaciones de alta incertidumbre y tensiones marcadas para el sistema democrático, que llevan a interrogarnos sobre la posibilidad de persistir o de romperse.

Easton (1999, p. 84), “considera como objetivo primordial del análisis político, comprender cómo y de qué manera los sistemas políticos logran subsistir". Parte de la premisa de que todos los sistemas políticos poseen estructuras especiales que contribuyen a regular las diferencias o imponen un arreglo según un conjunto de criterios. Pero sobre todo, dependerá de la capacidad del sistema para adjudicar valores en la sociedad y lograr su aceptación.

Easton conceptualiza al sistema político como: "el conjunto de pautas de interacción por medio de las cuales se asignan valores a una sociedad, y que las más de las veces los integrantes de una sociedad aceptan en su mayor parte esas asignaciones como autoritarias" (p. 125). Es importante aclarar que el término "autoritario" refiere en este caso al carácter imperativo y vinculante de las decisiones que adoptan las autoridades que gobiernan u ocupan roles activos en la política y son actores protagónicos en la gestión cotidiana del sistema político. Las decisiones que las autoridades adopten son consideradas

1. Según Gaitán (2010), las regresiones autoritarias suceden cuando en un país se retorna hacia medidas autoritarias que frenan el avance de la democracia. Para estudiar el comportamiento de las democracias establecidas en el mundo, el autor definió cuatro causas para entender tales
regresiones. Estas son: la continua corrupción (CC), la pobreza (CP), la restricción de libertades civiles (CL) y la concentración de poderes en la
figura del Poder figura del Poder Ejecutivo (CE). 
obligatorias por los actores afectados por ellas. En palabras de Easton (1999, p. 80), "El interés personal, la tradición, la lealtad, un sentido de la legalidad o de la legitimidad, son variables adicionales significativas para explicar por qué un sujeto se siente obligado a aceptar decisiones con carácter de autoritarias".

Entre los componentes básicos del sistema político, se encuentran: el conjunto de valores $\mathrm{y}$ de normas que justifican el tipo de régimen y determinan la manera como los miembros del sistema pueden participar en la política y resolver los conflictos; y las estructuras de autoridad que definen el rol y el comportamiento de aquellos que tienen la capacidad de ordenar y obligar. Las autoridades son las personas que ocupan las estructuras de autoridad.

Definido de esta manera, el sistema político opera bajo dos variables: 1) adjudicación de valores en la sociedad; 2) logro de su aceptación. Este sistema político se encuentra inserto en un ambiente que lo afecta y que logra alterarlo cuando hay diferencias no resueltas, lo cual exigirá cambiar algunos o la totalidad de sus aspectos para alcanzar su persistencia. En este sentido, el sistema reacciona y responde a las influencias que operan sobre él.

Easton determina que existen dos fuentes de tensión hacia el sistema político: una interna que deriva de las diferencias que surgen entre los factores que comprenden el sistema (valores, normas, comunidad, entre otros) a la hora de distribuir y utilizar los valores escasos. Y otra fuente de tensión que proviene de otros sistemas distintos al político (externos), la cual tiene que ver con los proyectos de modernización económica, las transformaciones sociales, entre otras, cuyo comportamiento agrega tensiones.

De acuerdo con Easton, el sistema político opera como una "caja negra" constituida por insumos y productos, siendo los insumos las demandas y apoyos hacia el sistema político, provenientes del interior del mismo y de otros sistemas de la sociedad, y los productos las decisiones y/o acciones que generan las autoridades frente a las demandas de otros sistemas y que asumen las formas de políticas públicas, leyes, programas de gobierno, entre otros. En la relación insumo/producto se generan tensiones cuando "las autoridades no están en condición de satisfacer en cierta proporción las demandas de los miembros o se resisten a hacerlo, esa situación provocará en definitiva un descontento cada vez mayor" (Easton, 1999, pp. 164-165).

El comportamiento del sistema político puede evaluarse a partir de los tipos de respuestas reguladoras que brinda la sociedad, al mostrar una actitud de apoyo o rechazo frente a las autoridades, el régimen político o el orden constitucional. Este apoyo es específico cuando la sociedad se muestra satisfecha al considerar que el sistema atendió sus demandas; mientras que el apoyo difuso se sostiene en vínculos de lealtad y afecto por la confianza que se tiene en la legitimidad del régimen y de la autoridad.

Para finalizar, Easton reconoce que para la persistencia del sistema político se requiere una retroalimentación con el resto de los sistemas que operan en la sociedad. Esto es, que la mejor forma de responder a las demandas y mantener los apoyos necesarios al sistema, será incorporando en las decisiones la información que deriva de dicha retroalimentación. Este enfoque sistémico se interesa principalmente por la estabilidad y el orden, por los mecanismos que posibilitan la "persistencia" de los sistemas políticos en un mundo de cambios $\mathrm{y}$ tensiones.

A continuación, se verá cómo pueden operar estas categorías conceptuales propuestas por Easton, al examinar el comportamiento del sistema político venezolano durante el período 1999-2020. Para ello, es necesario comprender los antecedentes que se inscriben en el período 1958-1998 y que están relacionados con el propósito de instaurar y mantener el régimen democrático-representativo, a partir de un ambiente consensuado entre los actores hegemónicos.

\section{E1 Sistema Politico Venezolano: 1958-1998}

Diversos análisis coinciden en señalar que el Sistema Político Venezolano que se desarrolló a partir de los años sesenta, se caracterizó por ser de conciliación de las élites políticas representadas por los partidos políticos en torno a un conjunto de acuerdos que estaban dirigidos a garantizar la permanencia de la democracia venezolana² (López

2. Venezuela registró una temprana transición hacia la democracia a través de un pacto elitista, facilitado por la existencia de una sociedad civil débil con bajos niveles de organización. La democracia pactada en Venezuela la hace fuertemente dependiente de los actores incluidos en el pacto, la naturaleza de las restricciones políticas durante el pacto (claramente establecidas en el Pacto de Punto Fijo y
afianzamiento de dichas restricciones en los diseños constitucionales (en este caso, la Constitución de 1961). 
Maya et al., 1989). Este sistema populista de conciliación es definido por Rey (1991, p. 543), como "un complejo sistema de negociación y acomodación de intereses heterogéneos, en el que los mecanismos de tipo utilitario iban a desempeñar un papel central en la generación de apoyos al régimen y, por consiguiente, en el mantenimiento del mismo". Representó históricamente la respuesta al dilema que se remontaba a comienzos del siglo $\mathrm{XX}$, entre una concepción elitista y otra populista sobre cómo conducir el proceso de modernización capitalistarentista del país, cuya respuesta fue a favor de un régimen democrático-populista que logró su estabilidad a partir de pactos y acuerdos ${ }^{3}$ suscritos por los principales actores políticos, económicos y sociales en el año 1958.

El Pacto de Punto de Fijo era la expresión del consenso entre los principales partidos políticos: Acción Democrática (AD), Comité de Organización Política Electoral Independiente (Copei) y Unión Republicana Democrática (URD), con el beneplácito de las Fuerzas Armadas Nacionales y la Iglesia, y con una menor participación de organizaciones de representación social como la Confederación de Trabajadores de Venezuela (CTV) o la Federación de Estudiantes (López Maya et al., 1989). Se trató de un acuerdo de unidad y cooperación que descansó sobre las siguientes consideraciones:

1. Un movimiento democrático nucleado en partidos políticos prestos a atender en conjunto los "intereses perdurables de la Nación" (Revista de Artes y Humanidades UNICA, 2005, p. 238), como garantía de que las deliberaciones políticas respondieran a las urgencias del país.

2. Compromiso en una política nacional que garantizara el proceso electoral respondiendo "a las pautas democráticas de la libertad efectiva del sufragio”. (s.a., 2005, p. 238)

3. El compromiso de $\mathrm{AD}$, Copei y URD en la defensa de la constitucionalidad y del derecho a gobernar conforme al resultado electoral, un Gobierno de Unidad Nacional y un Programa Mínimo Común.

4. La Unidad Nacional permitía incluir diversas candidaturas y planchas legislativas y para ello se creó la Comisión Interpartidista de Unidad, a los fines de velar por que no se dieran "desviaciones personalistas o sectarias en la campaña electoral" (s.a., 2005, p. 241).

5. En aras de promover las distintas opciones de candidaturas en los procesos electorales que los candidatos y programas se formulen en el marco del espíritu de la unidad para evitar pugnas interpartidistas que pudieran interferir en la formación del Gobierno de Unidad Nacional.

En definitiva, el Pacto de Punto Fijo persiguió garantizar el ejercicio del derecho electoral democrático en un clima de unidad, para así lograr la estabilidad y permanencia de la democracia en 1958. Con este Pacto, se sentaron las bases de un sistema democrático que apuntaló la transición política de Venezuela de la dictadura hacia la democracia. Según Brewer-Carías (1998, p. 12), "solo un sistema de Estado centralizado y de centralismo democrático de partidos era el que podía ser el instrumento para implantar la democracia”. Las circunstancias históricas justificaron los acuerdos establecidos por la élite política del país a finales de la década de los cincuenta.

El Programa Mínimo de Gobierno, por su parte, estableció los lineamientos económicos y sociales que debian guiar al candidato que resultara ganador en los comicios electorales del año 1958. El desarrollo socioeconómico del país descansaba sobre un modelo rentista que funcionaba gracias a los cuantiosos recursos económicos percibidos por el Estado a través de la renta petrolera y que permitió, mediante gasto público social, generar adhesiones al proyecto político democrático. Kornblith (1996, p. 9), señaló que "El modelo rentista permitió atender de manera relativamente satisfactoria, aunque desigual, las demandas y expectativas de diversos sectores sin generar conflictos distributivos".

Desde el punto de vista del sistema de partidos, la situación fue cambiando durante el período 1958-1998 (Molina, 2001). Si bien la instauración de la democracia estuvo acompañada por un pluralismo político moderado (1958-1973) en proceso de institucionalización con la presencia electoral de fuerzas partidistas como $\mathrm{AD}$, Copei,

3. Los principales acuerdos explícitos son: el Acta de Avenimiento Obrero-Patronal firmada el 24 abril de 1958 entre representantes de Fedecámaras y el Comité Sindical Unificado. El Pacto de Punto de Punto Fijo, firmado el 31 de octubre de 1958, entre representantes de los partidos AD, Copei y URD. La Declaración de Principios y Programa Mínimo de Gobierno, firmada el 6 de diciembre de 1958 por los candidatos presidenciales de los partidos $\mathrm{AD}$, Copei y $\mathrm{RD}$. La Ley de Concordato Eclesiástico, mediante el Convenio suscrito entre el Estado de Venezuela y la
marzo de 1964 entre representantes del Papa Paulo VI y el presidente Rómulo Betancourt (Lopez Maya et al., 1989). 
URD y en menor medida, el PCV, a partir de la década del sesenta, AD y Copei se consolidaron como las principales fuerzas políticas del país, estableciendo gradualmente un sistema bipartidista atenuado, no polarizado e institucionalizado (1973-1993), caracterizado por la alternancia en el poder de $\mathrm{AD}$ y Copei, logrando una definitiva institucionalización de estas fuerzas políticas; de igual manera, "se reduce la volatilidad electoral y se afianzan las lealtades partidistas" (Molina, 2001, p. 4).

A partir de 1993, por efecto de la crisis económica surgida en la década del ochenta que afectó la legitimidad de los partidos tradicionales en cuanto a su capacidad de responder a las demandas a partir de la distribución de recursos a través del gasto público, incidiendo a su vez en la estabilidad, la compenetración social, la legitimidad y la solidez organizativa de los mismos, el sistema de partidos entra en un pluralismo polarizado y desinstitucionalizado (1993 Actualidad), caracterizado por la presencia a nivel regional y municipal, gracias a la descentralización adelantada en Venezuela a partir de 1989, de nuevas fuerzas políticas de izquierda como es la Causa R y posteriormente, el partido Patria Para Todos (PPT), el Movimiento Guinta República (MVR) y el Partido Socialista Unido de Venezuela (PSUV), Primero Justicia, Proyecto Venezuela, Voluntad Popular, Un Nuevo Tiempo, entre otros partidos y movimientos políticos, con lo cual se revisita la polarización ideológica izquierda - derecha.

Este sistema de partidos se conjugó con un sistema electoral ampliamente favorecedor al posicionamiento de los partidos políticos como único mecanismo de mediación entre el Estado y la sociedad. De acuerdo con el Instituto Latinoamericano de Investigaciones Sociales (2010, p. 1), el sistema electoral se caracterizó durante el período estudiado por ser proporcional al asignarse "el número de escaños de un cuerpo legislativo o parlamento, de acuerdo con el porcentaje de votos que reciben los partidos o grupos políticos que participen en el correspondiente proceso de elección". También se caracterizó por aplicar un sistema de cocientes electorales que permitió la incorporación de partidos con poca fuerza electoral, como era el caso del Partido Comunista de
Venezuela (PCV). Bajo estas reglas de juego fueron favorecidos los partidos políticos más estables y más institucionalizados como fueron los casos de $\mathrm{AD}$ y Copei.

El éxito político que mostró el Sistema Político Venezolano durante el período de 1958 - 1998 radicó en su capacidad de manejar al Estado y a los recursos provenientes de la renta petrolera de acuerdo con los intereses del pacto de élites entre los partidos políticos no comunistas, las fuerzas armadas nacionales, la dirigencia del sector empresarial, del sector laboral y la iglesia católica. Por esta vía se logró mantener niveles aceptables de satisfacción de demandas sociales y de legitimidad política para garantizar la estabilidad y continuidad del régimen. Desde el punto de vista económico, el sistema político logró una transición hacia la modernización del país bajo un modelo democrático-populista que minimizó el conflicto entre los distintos actores hegemónicos en la sociedad. Logró, mediante la distribución de la renta del Estado y la puesta en práctica de políticas de concertación y consenso, evitar las contradicciones sociales propias de la transición hacia la modernización.

Luego de alcanzar la estabilidad de la democracia a partir de un conjunto de acuerdos, ¿Por qué la crisis del modelo? De acuerdo con Juan Carlos Rey (1991), el sistema populista de conciliación de élites dependió de la presencia y adecuada interacción de tres factores. Estos son: 1) la abundancia relativa de recursos económicos provenientes de la renta petrolera, que capacitaban al Estado para atender demandas de grupos y sectores heterogéneos. La crisis económica de la década del ochenta, con el descenso en los precios del petróleo y la maxidevaluación en febrero de 1983 con el llamado "viernes negro", fue mermando la capacidad distributiva de los gobiernos de turno, incrementando las demandas insatisfechas $\mathrm{y}$ afectando las relaciones entre los actores y, particularmente, afectó las lealtades partidistas que en definitiva minaron las expectativas de inclusión y ascenso social ofrecidas por la democracia que lideraron los partidos políticos; 2) un nivel relativamente bajo y relativa simplicidad de tales demandas, que permitió que fueran

4. A partir de 1981, hubo un descenso en los precios del petróleo y se inició la crisis de la deuda externa en América Latina. Con este contexto internacional, aunado a factores internos que daban cuenta de la situación de agotamiento del modelo de acumulación capitalista rentístico al hacerse insuficiente la renta para reproducir dicho modelo, se adoptaron el viernes 18 de febrero de 1983 medidas de control de cambio y a partir de alli se presentralidad que había asumido el Estado en la vida política, económica y social del país. 
satisfactoriamente atendidas con los recursos disponibles; y 3) la capacidad de las organizaciones políticas (partidos y grupos de presión) y de su liderazgo para agregar, canalizar y representar esas demandas, asegurando la confianza de los representados.

En definitiva, se afectaron negativamente, de manera simultánea, estos tres factores, lo que dio lugar a la crisis en el sistema político y amenazó su estabilidad. Más aún, el propio sistema mostró carecer de mecanismos, instituciones y reglas que le permitieran funcionar fuera de un contexto de abundancia económica.

Tal como lo plantea Easton (1999, p. 121), “...los sistemas políticos pueden mantenerse estables por un lapso de tiempo determinado, pero no indefinidamente inalterables". Esto se confirma con el caso venezolano para el período 1958-1998. Para entonces, su sistema político estuvo signado por un ambiente o un tipo de relación dominante en la sociedad venezolana caracterizada por ser conciliatoria entre las élites representativas de los principales actores hegemónicos del país. Los pactos establecidos estaban orientados a garantizar la estabilidad de la democracia, conjugando el proyecto de modernización política con el de modernización económica.

$\mathrm{El}$ instrumento para lograr dichos objetivos fue el sistema de representación partidista, que logró darle legitimidad al modelo, a partir de los procesos electorales que fungían como factor estabilizador importante y regulador dentro del conflicto de contradicciones sociales, y que evidenciaban la lealtad hacia los partidos y la adhesión a las reglas del juego democrático por parte de la sociedad. En cuanto a los apoyos específicos, el Sistema Político Venezolano contaba con la adhesión de las organizaciones políticas y sociales, la red clientelar establecida y las asociaciones de interés que fueron corporativizadas por el Estado ${ }^{5}$.

Sin embargo, la crisis política, económica y social experimentada en Venezuela a partir de la década del ochenta introdujo serias tensiones hacia el sistema político, afectando sus mecanismos de retroalimentación. Esto dio lugar al surgimiento de nuevos actores y liderazgos con un proyecto de sociedad anclado en mecanismos distintos a los pactos y acuerdos que prevalecieron en el período 1958-1998.

Ahora bien, ¿qué sucede con el Sistema Político Venezolano a partir de 1999? ¿Cómo este se enfrenta a las tensiones que introducen el proyecto político revolucionario y socialista impulsado por Chávez y Maduro? ¿Es posible que dichas tensiones y las respuestas que genera el sistema político frente a ellas permitan la persistencia del sistema democrático o signifiquen su transformación hacia un sistema distinto? A continuación, se examina el contexto para intentar responder a estas interrogantes.

\section{El Sistema Político Venezolano: 1999- 2020}

Con la llegada al poder de Hugo Chávez en las elecciones presidenciales de 1998 y su ratificación por la vía electoral en períodos sucesivos, se ha venido apuntalando un modelo que pretende ser alternativo al modelo de conciliación de élites sobre el cual se sostuvo el Sistema Político Venezolano a partir de 1958. Entre los rasgos más sobresalientes del proyecto político liderado por Chávez se encuentran: un liderazgo personal, una amplia movilización popular y la proclamación de una nueva institucionalidad.

En efecto, el presidente Chávez impulsó un programa político que prometía liquidar la corrupción que se había apoderado de la vida pública venezolana desde la puesta en vigencia del Pacto de Punto Fijo. El instrumento de cambio político y social propuesto fue el Proceso Constituyente, sobre el cual el presidente Chávez (1999, p. 9), afirmó: “¿Para qué la constituyente? Para refundar la República, relegitimar el poder y rehacer la democracia mediante una nueva Constitución”. Se trataba de refundar la república en la perspectiva en que ha sido concebida por los gobiernos populistas; es decir, en el sentido del recomienzo histórico nacional. Al tiempo que toma fuerza el eje discursivo de las izquierdas con el enfoque de derechos que predominó en su proyecto constitucional, aupando la participación y el protagonismo ciudadano como motor de la transformación revolucionaria.

5. Las prácticas clientelares en Venezuela obedecen a grupos dentro del Estado o relacionados con él que entraron en una relación (no formal o legalizada) de intercambio de bienes y servicios con algunos sectores de las clases populares. Los bienes y servicios son de tipo no comparables (generalmente, prebendas económicas por apoyo político). A esto se suma que las organizaciones de los sectores populares y una gran parte de las organizaciones de la clase media, en la práctica fueron corporativizadas, comprometiendo su autonomía y generando una gran dependencia de los
partidos políticos en la atención a sus demandas (Hanes de Acevedo, 1988). 
Según Deborah Norden (2008, p. 177), "La revolución de Chávez ha avanzado de arriba abajo, cambiando una democracia fuerte por un gobierno concentrado que enfatiza los objetivos revolucionarios y debilita los controles democráticos". Esto se confirma no solo con el Proceso Constituyente adelantado, sino porque el presidente Chávez desde un comienzo se desmarcó de la democracia liberal representativa $\mathrm{y}$, en efecto, la concepción de democracia participativa y protagónica implícita en el proyecto chavista supuso un cambio en el Sistema Político Venezolano capaz de instrumentar los canales que hiciesen posible tal empresa.

La definición "revolucionaria" de su proyecto político dio lugar a un contexto distinto a lo que fue la conciliación entre élites que caracterizó el período precedente a su arribo al poder. Este proyecto descansa en la exclusión tanto de los actores tradicionales relacionados con la democracia representativa y con la llamada etapa puntofijista (esto es, los partidos políticos), así como el condicionamiento de los actores sociales que pueden ser o no reconocidos por el gobierno, en tanto y en cuanto se declaren seguidores y adeptos a su proyecto. En consecuencia, estamos frente a un escenario que desde sus inicios se configuró como conflictivo y sobre todo, fragmentado y polarizado $^{6}$, ya que la nueva dirigencia política del país no mostró estar dispuesta a reconocer ni mucho menos procesar las demandas provenientes de los sectores considerados como opositores al gobierno.

El posicionamiento político de Chávez tras su triunfo electoral de 1998, se dio por la vía del Proceso Constituyente y de una nueva Constitución sancionada por la Asamblea Nacional Constituyente a finales de 1999, que sirvió para sentar las bases de los cambios que más adelante se fueron instrumentando. Entre estos cambios destaca la constitucionalización de la democracia participativa y protagónica, en detrimento de la relación de la sociedad con los partidos como mecanismo privilegiado de representación política. La propuesta política de Chávez en su primer año de gobierno se centró en sancionar una constitución que rigiera los destinos de la V República, Constitución que debía ser incluyente, centrada en el protagonismo de los ciudadanos y ser expresión de los intereses de la sociedad en su conjunto (Chávez, 1999). Sin embargo, se aprobó una Constitución que se encuentra:

Envuelta en un discurso participativo y antipartido, se caracteriza por ser una Constitución autoritaria que como lo expresamos al sancionarse, es el resultado de la combinación de un sistema de concentración del poder, de centralización del Estado, de sistema presidencial exacerbado, de estatismo extremo en paralelo al marginamiento de la sociedad civil, de populismo petrolero y de militarismo inusitado (Brewer-Carías, 2005, p. 7).

Pero este propósito inicial fue cambiando en la medida que la polarización política fue escalando y fueron creciendo las demandas insatisfechas de diversos sectores de la oposición. En la campaña electoral de 1998, Chávez impulsó un discurso dicotómico expresado en el pueblo vs. la oligarquía, y los proyectos políticos se expresaron también como antagónicos (continuidad vs. cambio radical). Entre los años 2001 y 2004 el país experimentó una fuerte agitación política que tuvo como expresiones el Paro Petrolero y la interrupción y retorno de Chávez en el poder a causa de la búsqueda de la salida de Chávez por vías no constitucionales ${ }^{7}$.

Estos eventos que amenazaron la estabilidad del sistema dieron lugar a la realización del referendo revocatorio a Chávez (agosto de 2004), siendo el presidente favorecido y fortalecido en su liderazgo frente a las masas que lo acompañaban ${ }^{8}$. Asimismo, su proyecto, que en un principio se relacionó con un populismo anclado en un mayor gasto social y las misiones sociales entre los años

6. La polarización política es una variable de peso en la crisis del sistema político venezolano actual. La misma se asienta sobre desigualdades sociales a las que visibiliza y utiliza con fines políticos. Desde la llegada de Chávez al poder, Hernández (2005, p. 99), afirma que "el país se encuentra sometido a un continuo debilitamiento de los vínculos sociales...que tornan difícil la convivencia democrática e impiden la conformación de una idea de futuro compartido por la mayoría de la población". Al menos tres etapas ha identificado López Maya (2010, p. 8) en el desarrollo de la polarización politica en Venezuela: I) etapa de creación de condiciones para su emergencia (años 80 y 90); II) etapa como estrategia en la lucha hegemónica (1998-2005) y;

7. etapa como instrumento para imponer el socialismo del siglo XXI (de 2005 hasta hoy)

El caracter nacionalista y estatista que caracterizó la propuesta política del presidente Chávez generó desde su campaña electoral de 1998, confrontación con diversos grupos economicos cuyos intereses se verian afectados con las políticas reguladoras y de control estatal que se materializan con las leyes habilitantes aprobadas en noviembre de 2001 . Estas fueron detonante de un mayor descontento y movilizacion social que que culminó con heridos y muertos en las adyacencias del Palacio de Miraflores en Caracas y al día siguiente el Presidente Chávez sale del poder. que culmino con heridos y muertos en las adyacencias del Palacio de Miraflores en Caracas y al dia siguiente el Presidente Chavez sale del poder.

8. La revocatoria de mandato es un mecanismo de control ciudadano hacia sus gobernantes elegidos, que se introdujo en Venezuela por primera vez en la Constitución Nacional impulsada por el presidente Chávez en 1999 y que la oposición política del país activó en el año 2002 , pero el Tribunal Supremo de Justicia desconoció esta iniciativa prevista para febrero de 2003 para llevarse finalmente a cabo en el 2004 . En medio del clima de disputa entre gobierno y oposición, las partes aceptan el referéndum revocatorio como una salida pacífica y democrática a la crisis. El resultado fue el rechazo a la destitución con un 59,10\% de los votos válidos, con lo cual el presidente Chávez fue ratificado en su cargo. 
2003 y 2005, transitó hacia una propuesta más radical como la del "socialismo del siglo XXI", que a partir del año 2007 comienza a vincularse con un modelo de economía socialista que no ha hecho otra cosa que mantener vigente el modelo asistencialista que caracterizó al período 1958-1998. Hasta ahora no se ha logrado compensar y complementar en el futuro una economía nacional independiente de la producción petrolera; por el contrario, ha logrado maximizar el control de los ingresos externos y fiscales de origen petrolero.

Para poder avanzar en la ejecutoria transformadora que imprime el signo de su liderazgo, el gobierno de Chávez ha necesitado la constitución de nuevos arreglos que permitieran prolongar el reparto de la renta y el garantismo estatal. Solo así, la conflictividad y el desgaste político implícitos en su ejecutoria transformadora podían compensarse con la compra de legitimidad asociada al reparto (Vera, 2005, pp. 33-34).

En cuanto a la legitimación del Proyecto Bolivariano, este ha sido por la vía refrendaria que inició con el referendo consultivo para convocar una Asamblea Nacional Constituyente (1999); el referendo consultivo (diciembre de 1999) para aprobar la Constitución; el referendo revocatorio (agosto de 2004), y el referendo consultivo para reformar la Constitución (2007) (Lissidini, 2008). En tanto "su legitimidad se apoya en la popularidad personal, la práctica extendida de relaciones clientelares con un electorado cautivo y las relaciones de exclusión hacia la oposición política” (Ramos, 2011, p. 3). La competitividad electoral fue una característica en la gestión gubernamental del presidente Chávez; sus instrumentos fueron ideológicos, económicos, de innovación política y una gestión gubernamental que mantuvo el voto popular cautivo y que permitieron una amplia movilización popular a favor del gobierno.

Desde el punto de vista institucional, el apoyo partidista a Chávez estuvo inicialmente relacionado con el Movimiento Quinta República (MVR) y con el apoyo de partidos y movimientos de izquierda que se articularon en torno al llamado Polo Patriótico. Pero ha sido marcado el apoyo del sector militar hacia el proyecto de Chávez, "asumiendo un protagonismo tanto en el liderazgo político como en la nueva élite burocrática del país” (Rivas, 2012, p. 16).

Dado el carácter personalista que ha asumido la política en tiempos de Chávez, el sistema de partidos en Venezuela dejó de ser multipartidista inestable para ser de partido predominante (Sánchez, 2009) con la creación del Partido Socialista Unido de Venezuela (PSUV) en el año 2008. Este modelo se refuerza o favorece con un sistema electoral mixto que combina en su seno elementos del sistema de representación por mayoría, con elementos del sistema de representación proporcional.

\begin{abstract}
El sistema electoral... tenderá a beneficiar al partido mayoritario. Si el PSUV continúa como partido predominante, manteniendo los niveles de votación que ha obtenido en los últimos procesos electorales, el sistema beneficiará al PSUV. Si, por el contrario, surge otro partido o se conforma una coalición que sea capaz de acumular la mayoría, entonces será esta la que se beneficie del sistema (Sánchez, 2009, p. 96).
\end{abstract}

La conflictividad política y social derivada por la oposición de amplios sectores de la población al proyecto revolucionario y socialista llevaron a proponer una Reforma Constitucional en el 2007 que fue calificada por los analistas y expertos como la vía para radicalizar los cambios en el Estado y en todo el Sistema Político Venezolano. Esta propuesta fue rechazada en referéndum consultivo, pero luego se fue materializando fuera del marco constitucional, a través de leyes orgánicas. Entre las modificaciones formales que durante el mandato de Chávez se introdujeron hacia el sistema político se encuentran: en primer lugar, el debilitamiento de la separación de poderes; todos los poderes están concentrados en funcionarios identificados con el proceso chavista, por lo cual no funcionan los contrapesos. En Venezuela, con la Constitución aprobada en 1999, se sumaron a los poderes públicos tradicionales (Ejecutivo, Legislativo y Judicial) dos nuevos poderes: el Ciudadano, constituido por la Contraloría General de la República, la Fiscalía General de la República y la Defensoría del Pueblo, y el Poder Electoral, constituido por el Consejo Nacional Electoral.

En segundo lugar, el fortalecimiento del personalismo, el ejecutivismo y el centralismo: el presidente se erige como mecanismo de cohesión social y a través de leyes habilitantes y de decisiones en distintas materias pone en evidencia estas características que le ha impreso al sistema político.

En tercer lugar, la exclusión y la discriminación política. Dos ejemplos claros son la lista Tascón, que "derivó en el uso político discriminatorio de la lista de venezolanos que 
suscribieron la convocatoria al referéndum revocatorio del presidente en el 2004" (Aponte y Gómez, 2009, p. 8). La otra lista es la de Russián, que contemplaba más de 200 inhabilitaciones políticas que impiden a opositores postularse a cargos de elección popular.

$\mathrm{Si}$ los representantes políticos y las organizaciones de la sociedad civil son las que articulan, agregan y codifican las demandas sociales dirigidas al sistema político, al accionar tienen la posibilidad de facilitar, obstaculizar o impedir que dichas demandas lleguen a la autoridad. Dentro del sistema, estos representantes y organizaciones son instrumentos que promueven y mantienen la distribución de recursos y valores. Entonces, habrá un sector (pro gobierno) que termina percibiendo al sistema político como una ventana de acceso a recursos materiales y simbólicos para sus miembros. En cambio, otros sectores políticos y sociales que no comulgan con el proyecto revolucionario y socialista creen que sus demandas no logran penetrar en el sistema, generando insatisfacción y descontento por la gestión gubernamental.

En cuarto lugar, el ventajismo electoral, el cual está relacionado con la parcialización del árbitro electoral que constituye un obstáculo a la hora de atender las demandas de los sectores opositores al gobierno. Este resulta en un aspecto relevante debido a que, en 13 años de gobierno, Chávez enfrentó 14 procesos electorales que, a excepción del referendo consultivo para la Reforma Constitucional de 2007, le resultaron favorables.

En quinto lugar, los ensayos de control social. Frente a las organizaciones tradicionales existentes en el país, el gobierno propuso organizaciones paralelas y denominadas bolivarianas, a las cuales reconoce como interlocutores válidos, excluyendo otras formas preexistentes. En la medida en quelas organizaciones sociales pasaron a ser parte del paraguas del Poder Popular, estas tomaron la forma de instancia de mediación de la sociedad civil y pasan a ser parte del sistema político, al ser convertidas en operadores políticos de la autoridad. El retiro de apoyos específicos tiene que ver con esta realidad; hay muchos sectores que ya no intentan convertir en demandas sus intereses particulares porque el sistema se ha cerrado a la retroalimentación de sectores que no manifiesten estar alineados con la revolución y el socialismo.

A partir de este conjunto de elementos, podemos derivar que el ambiente polarizado sobre el cual funcionó el Sistema Político Venezolano bajo la presidencia de Chávez fue fuente permanente de descontento, ya que los valores que asignó el gobierno al resto de la sociedad se correspondían únicamente con su proyecto y sus intereses, dejando por fuera las demandas provenientes del resto de la sociedad considerada como opositora. En consecuencia, estos valores no fueron aceptados y en la medida en que se incrementó y se prolongó la insatisfacción por demandas no atendidas se comprometió el apoyo difuso al sistema. De acuerdo con Easton, en Venezuela no se estaría dando un equilibrio entre insumos (demandas) y productos (politicas, decisiones gubernamentales), y el intercambio del sistema político con los demás sistemas de la sociedad es limitado, dadas las características personalistas y autoritarias durante la gestión gubernamental de Chávez.

En un contexto altamente polarizado, al gobierno le resultó favorable recurrir al apoyo difuso para hacer frente a los momentos de conflicto. Esto quiere decir que la legitimidad del régimen y de la autoridad durante los sucesivos gobiernos del expresidente Chávez se sostuvieron sobre vínculos de lealtad y afectos, más que por el apoyo específico que deriva de la satisfacción por las demandas atendidas de los diversos sectores de la población.

El punto de inflexión estuvo en el carácter excluyente del proyecto político de Chávez, por lo que el sistema político seguirá, en una etapa post Chávez, alterándose y colocando en ciernes la permanencia de la democracia, en la medida en que se continúen erosionando los mecanismos fundamentales del juego democrático. Easton (1999, p. 134), plantea que en la práctica es difícil discernir "cuando el sistema se acerca al punto crítico más allá del cual se transforma en un sistema diferente".

La muerte del presidente Chávez en marzo de 2013 abrió una nueva disputa por la hegemonía política en el país y el movimiento denominado chavismo entró en un debate entre la renovación y las rupturas internas que han incidido en la manera de operar del Estado, su forma y su composición. Acaso, ¿estos cambios colocan al sistema político en el punto crítico?

\subsection{La etapa post-Chávez y el rostro de las nuevas formas de autoritarismo en Venezuela}

Lo que en primera instancia parecía ser la continuidad del proyecto revolucionario y socialista de Chávez, con un candidato designado por él mismo 
antes de su muerte, mostró de manera prematura la presencia de contradicciones y tensiones dentro del chavismo, que darían un giro importante a la forma de gobernar y de dirigir el proyecto político.

Con el fallecimiento del presidente Chávez en el 2013, es electo Nicolás Maduro, quien se erige como el garante del legado de Chávez y la continuación del proyecto de transformación socialista en el país. El triunfo electoral sobre el candidato opositor fue de apenas el 1,59\%, lo cual hace ver que electoralmente el chavismo había retrocedido en el apoyo electoral. En términos prácticos esto significó, en un contexto de acelerado deterioro de las condiciones sociales, económicas y políticas del país (hiperinflación, la paralización parcial de la industria petrolera con su afectación a los ingresos petroleros, períodos de violencia tras amplias movilizaciones de sectores opositores en el país), fuertes demandas hacia el Sistema Político Venezolano que, en lugar de ser atendidas y procesadas, dieron lugar a que se tejiera una estructura legal que justificó la represión a cualquier forma de reclamo hacia el gobierno y un bloqueo constante a los canales pacíficos y democráticos para la resolución de los conflictos en Venezuela. Pero, ¿qué ha pasado para que se radicalice el talante autoritario dentro del socialismo bolivariano, tras la muerte de su líder, Hugo Chávez?

Para intentar responder a esta interrogante, es necesario tener en cuenta que las condiciones existentes en el país para el momento en que asume Maduro el poder son adversas y este no poseía las cualidades personales de Chávez para fungir como eje articulador de la vida nacional, y siendo la prioridad dar continuidad a su mandato presidencial, Maduro le ha sacado mayor provecho al legalismo autoritario, que no es otra cosa que el establecimiento de regulaciones legales con el fin de incrementar su capacidad de control sobre la sociedad; en otros términos, al uso que hacen los estados totalitarios de la ley para lograr sus objetivos de supresión progresiva de la libertad hasta alcanzar la dominación total (Arendt, 2004).

Bajo esta consideración, existen tres aspectos claves. El primero de ellos tiene que ver con las tensiones a lo interno del chavismo, que a todas luces su líder Chávez supo manejar y que por los cuantiosos ingresos petroleros manejados por el gobierno logró mantener tales tensiones en sus cauces, pero una vez que este desaparece se hizo evidente que venían coexistiendo dos corrientes dentro del movimiento revolucionario que le han dado un giro importante a la forma de gobernar. Según Velasco (2017, p. 11), la primera corriente liderada por Chávez estaba "anclada en la Constitución de 1999, que promovía el protagonismo a punta de redistribución de recursos para continuar legitimándose en las urnas". Mientras que, la segunda corriente, encarnada en el liderazgo chavista que asume el poder en la etapa post-Chávez con una visión socialista radical que "apelaba a valores anti individualistas y anti consumistas, abandonaba las pretensiones pluralistas, excluía a quienes se interponían en la vía del cambio profundo y visualizaba de manera creciente la Constitución de 1999 como un documento limitante" (Velasco, 2017, p. 11).

En esta segunda corriente se ubica Maduro, un sindicalista y militante de la izquierda radical, cuya figura es manejada en un segundo plano al no tener el carisma y la ascendencia ante el pueblo que tuvo Chávez (Arenas, 2016), y se exalta el legado de este último para hacer frente al mandato de mantener el poder y lograr legitimidad en condiciones muy desfavorables, ya que, por una parte, la corrupción e ineficiencia del aparato burocrático del Estado erosionó la promesa de materializar los cambios estructurales, sustanciales y revolucionarios prometidos e incluso la mayor promesa del proyecto chavista, que el Poder Popular gobernara, no se concretó.

Por otra parte, las previsibles luchas internas que podían surgir tras la ausencia de Chávez entre facciones militares y civiles por la sucesión en el poder fueron manejadas por Maduro apelando, como ya se mencionó, a la figura de Chávez y al mantenimiento de la identidad con el proyecto político que este delineó. También incorpora estrategias para distribuir el poder y los recursos entre las facciones del movimiento.

(...) la oficialidad militar activa; la familia Chávez; los diferentes grupos de izquierda; los veteranos de los intentos de golpe de Estado en 1992, debut público del movimiento bolivariano, entre los cuales destaca el controversial Diosdado Cabello, actual presidente de la Asamblea Nacional. En este sentido, el liderazgo carismático que caracterizó la presencia de Hugo Chávez en el poder ha sido sustituido por un novedoso elemento corporativo, 
que el presidente Maduro en su ortodoxia ha denominado gobierno colectivo, restringiendo el tradicional margen de maniobra presidencial (Tell, 2014, p. 10).

El segundo elemento para considerar en la estrategia política seguida por Maduro es el uso del resto de los Poderes Públicos para esquivar la "incertidumbre electoral", a partir del revés electoral que sufrió el chavismo con el triunfo de la oposición en las elecciones parlamentarias del 2015, pero que ya se había hecho notar por la estrechez de la victoria electoral de Maduro en las elecciones del 2013 con un 50,61\% vs. 49\% de Capriles. Este resultado, a pesar de haber sido impugnado por la oposición, no fue escrutado en sus actas. Las protestas en el 2013 adquieren contenido político ante el reclamo ciudadano por una auditoria a los resultados electorales, para ese año el Programa Venezolano de Educación-Acción en Derechos Humanos cuantificó 13 personas asesinadas en el marco de estas protestas y por primera vez se aplicó a los manifestantes la Ley Orgánica contra la Delincuencia Organizada y Financiamiento al Terrorismo, a petición expresa de la Fiscal General de la República, otro poder al servicio del gobierno.

Ante el retroceso en el apoyo electoral y la pérdida del monopolio del poder institucional que el chavismo tenía sobre los poderes públicos con el triunfo de la oposición en las elecciones parlamentarias del 2015, Maduro apostó al legalismo para mantenerse en el poder, utilizando al Tribunal Supremo de Justicia (TSJ) para emitir una sentencia que desconocía al Poder Legislativo ${ }^{9}$ y fue más allá, convocando una Asamblea Nacional Constituyente (ANC) en mayo de 2017, la cual se ha extralimitado en sus funciones, haciendo su trabajo a favor del Ejecutivo. Su convocatoria obedece:

(...) no por compromiso entre elites chavistas y proyecto revolucionario, sino por las necesidades de supervivencia en el poder, en momentos en que la ineficiencia y la corrupción, siempre a la vista para las bases más cercanas al gobierno, no pueden pensarse como problemas de ejecución sino como hechos estructurales. No obstante, sucede. Y ante la posibilidad de hacer valer aquellas propuestas de cambio radical, sectores de izquierda de base participaron de la convocatoria de Maduro, en medio de una guerra de poderes (...) Corrupción, inseguridad e ineficiencia aunado a profundos desequilibrios económicos que se expresan en el deterioro del poder adquisitivo del venezolano debido a una inflación descontrolada que durante los últimos años de Chávez en el poder no se atendieron y que con el presidente Maduro se han profundizado (Velasco, 2017, pp. 11-12).

La Asamblea Nacional Constituyente no es solo un poder legislativo paralelo, sino que se viene comportando como un suprapoder al que se supeditaron todos los poderes constituidos (salvo la Asamblea Nacional electa legitimamente en el 2015), ya que sus competencias rebasan la redacción de un nuevo texto constitucional y se ha dedicado a sancionar leyes, convocar elecciones, allanar la inmunidad parlamentaria de diputados opositores electos en el 2015, recibir la Memoria y Cuenta anual del Presidente de la República, aprobar el presupuesto nacional, entre otras facultades que violan flagrantemente la Constitución Nacional vigente que establece la separación y autonomía de los poderes públicos, además de los alcances y competencias que debe tener una Constituyente.

$\mathrm{El}$ país siguió sucumbiendo al autoritarismo, con la promulgación del Decreto de Estado de Excepción y Emergencia Económica (enero 2016), que dotó al Poder Ejecutivo de poderes extraordinarios discrecionales frente a lo que dicho poder considere como acciones desestabilizadoras que atenten contra la seguridad y la soberanía nacional, para posibilitar la adopción de medidas de seguridad pública y planes especiales; además de aprobar leyes sin consultar a la Asamblea Nacional de mayoría opositora, minando sus competencias. Este Decreto se renovó de manera sucesiva con el aval de la Sala Constitucional del Tribunal Supremo de Justicia y sirvió de argumento jurídico para la fuerte represión durante las protestas ciudadanas antigubernamentales que se llevaron a cabo en el 2017.

Nicolás Maduro participó en elecciones una vez que ensayó con acierto en las elecciones de gobernadores de octubre de 2017 una fórmula para ganar siendo minoría, ilegalizando candidatos y partidos, impidiendo y desalentando el ejercicio

9. De acuerdo con un Informe Especial de la Asamblea Nacional (2021), el Tribunal Supremo de Justicia emitió 76 sentencias en contra de sus decisiones y miembros; fueron suspendidos 3 diputados, 5 exiliados, 20 heridos, 4 presos, 4 asaltos al hemiciclo, 6 privados de inmunidad parlamentaria, aunado dentro del país. 
del voto, y finalmente alterando y revirtiendo resultados. Ante estas prácticas irregulares, la comunidad internacional y la oposición venezolana exigieron condiciones de transparencia, equidad y autonomía del Consejo Nacional Electoral (CNE) y un acompañamiento internacional al cual no estuvo dispuesto a someterse Nicolás Maduro y aun así fue relecto en los comicios presidenciales del 20 de mayo de 2018, profundizando aún más la crisis y el descontento popular que ha alcanzado las propias filas del chavismo con una disidencia ante la cual Maduro no ha sido tolerante y ha adoptado medidas de expulsión a miembros del partido de gobierno como han sido los casos de la exministra Ana Elisa Osorio, la periodista Vanessa Davies, la exgobernadora Antonia Muñoz, entre otros; y en casos extremos encarcelándolos, como ha sucedido con el periodista y militante del PSUV Nicmer Evans, el exmayor general Manuel Rodríguez Torres, entre otros.

Si bien Maduro no abolió el derecho al sufragio, lo despojó de su significado democrático al impedir que participaran libremente todos los sectores que desearan hacerlo sin exclusiones más allá de las legales, por la vía de inhabilitaciones de candidatos y partidos políticos, entre otras acciones. En la actualidad la salida electoral no es una opción, en tanto el Poder Electoral siga colonizado por el gobierno. Con el resto de los poderes públicos, como el Judicial, la situación no es distinta; se ha alentado el protagonismo de los órganos jurisdiccionales para preservar el poder del jefe de gobierno y autorizar, legalizar o constitucionalizar las medidas arbitrarias o contrarias al derecho como reelección indefinida, inhabilitaciones políticas, proscripción de partidos políticos y otros mecanismos antidemocráticos.

El tercer elemento es el incremento de la polarización, lo cual hizo más intransigente a la oposición que apeló a la convocatoria de movilizaciones exigiendo un cambio político en el país. Durante el 2014 se llevaron a cabo protestas masivas y pacíficas en rechazo al gobierno; el resultado fue una escalada de violencia y represión por parte de los cuerpos de seguridad del Estado, de grupos paramilitares y civiles armados con un saldo de 3.306 manifestantes detenidos, 973 heridos y 42 fallecidos y, según el Observatorio Venezolano de Conflictividad Social (2014), el gobierno justificó sus acciones represoras señalando que era necesario mantener el orden interno frente a protestas que catalogó de violentas, con objetivos insurreccionales y con fines desestabilizadores.

En el 2016 la oposición venezolana promovió el Referéndum Revocatorio al mandato de Maduro. Sin embargo, el Consejo Nacional Electoral y los tribunales bloquearon esta iniciativa, lo cual hizo que escalara el descontento y que en el 2017 (entre abril y julio) se llevaran a cabo en Venezuela protestas masivas y pacíficas convocadas por la Mesa de la Unidad Democrática, exigiendo un cambio político. De acuerdo con el Programa Venezolano de Educación-Acción en Derechos Humanos (2018), en el contexto de estas protestas fallecieron 139 personas y 3.802 personas resultaron heridas por la fuerza letal empleada por cuerpos de seguridad del Estado y civiles armados. Además, se usó la justicia militar para procesar a civiles violando el derecho a la defensa y al debido proceso.

El gobierno de Nicolás Maduro consolida la represión y criminalización a través de la implementación del Plan Cívico-Militar Zamora $200^{10}$. Según el Observatorio Venezolano de Conflictividad Social (2017), con dicho Plan se "institucionaliza la actuación conjunta de fuerzas militares, fuerzas milicianas y civiles armados en funciones de control de orden público", donde se logró confirmar la participación violenta de grupos paramilitares en 523 protestas entre abril y julio de 2017. De esta manera se criminaliza la protesta en el país y esta pasa a ser considerada como amenaza al orden interno.

La negativa de la Mesa de la Unidad Democrática (MUD) de participar y mucho menos reconocer los resultados de las elecciones presidenciales de 2018 donde fue reelecto Maduro debido a la ausencia de criterios de confianza e imparcialidad, agudizaron la crisis presidencial con la decisión el 23 de enero de 2019 de juramentar al entonces presidente de la Asamblea Nacional electa en el 2015, el diputado Juan Guaidó, como presidente interino ${ }^{11}$, quien fue respaldado por

10. Este Plan fue aprobado por Maduro el 18 de abril de 2017 , un día antes de la movilización convocada por la oposición; su objetivo sería "derrotar el la Constitución, otorga a civiles la seguridad del país, que es competencia exclusiva de la Fuerza Armada Nacional y los órganos de seguridad de Estado.

11. Ante los desaciertos en las estrategias seguidas y la enorme frustración al no lograr la salida de Maduro del poder, el liderazgo de Guaidó permitió reagrupar y reorganizar a las fuerzas políticas opositoras del país liderando una agenda en torno a tres objetivos: cese de la usurpación, transicion democrática y elecciones libres y transparentes; no obsta 
los ciudadanos en una marcha masiva y con el respaldo de presidentes y gobiernos de distintas partes del mundo. Tras varios intentos fracasados de negociación entre gobierno y oposición para buscar una salida democrática a la profunda crisis político-institucional del país, el gobierno de Maduro no mostró intención de ceder en nada, manteniendo al país y a sus habitantes en una gran incertidumbre sobre la salida a la profunda crisis que le afecta.

En resumen, estos tres elementos: 1) el ascenso al poder de un ala radical de la izquierda dentro del chavismo que frente a las condiciones adversas, lucha por mantenerse en el poder; 2) la negativa del gobierno a reconocer las competencias constitucionales y los espacios políticos obtenidos electoralmente por la oposición (especialmente en el Poder Legislativo) y, frente a los polémicos resultados de la elección presidencial de abril de 2013, donde el estrecho margen de victoria obtenido por Nicolás Maduro fue exonerado de toda fiscalización posterior, exacerbando en la sociedad opositora las dudas acerca de la idoneidad y transparencia del sistema electoral, así como de la posibilidad de acceder al poder por esa vía; y, 3) el incremento de la polarización con la consecuente radicalización de la oposición que se negó a participar y mucho menos reconocer los resultados de las elecciones presidenciales de 2018, dejan en evidencia que el autoritarismo ha sido un proceso incremental que se ha convertido en una herramienta para gobernar.

En efecto, la pérdida de competitividad electoral fue un incentivo para que el gobierno de Maduro mostrara su lado autoritario; si no puede competir, reprime. Es evidente el agotamiento de los principales recursos de los que se valió el chavismo para gobernar desde 1999: lo ideológico (mantener viva la identidad con el proyecto revolucionario y socialista pasa a un segundo plano, frente a nuevos escenarios la prioridad es mantener el poder); y los recursos económicos (hiperinflación, la paralización parcial de la industria petrolera que ha impactado negativamente en los ingresos petroleros, sanciones económicas internacionales) para el reparto de la renta han disminuido. Con el trascurso del tiempo se han venido usando prácticas autoritarias con mayor frecuencia.

El gobierno de Nicolás Maduro ha desarrollado políticas y prácticas destinadas a erosionar y blo-quear el avance de la democracia en Venezuela. A pesar de insistir en mantener una apariencia democrática al promover y participar en procesos electorales para darle legitimidad a su gobierno, el nivel de daño que ha hecho a las instituciones democráticas fundamentales han llevado al país a un abismo donde no existe ni un marco constitucional ni instituciones aceptadas ni por gobierno ni por oposición que permitan dirimir los conflictos de forma constitucional y democrática. Ante esto, el gobierno sigue profundizando en sus prácticas autoritarias. ${ }^{12} \mathrm{~A}$ diferencia de lo sostenido por Easton (1999), el gobierno de Nicolás Maduro ha demostrado en la práctica que sí se puede advertir la transformación del Sistema Político Venezolano hacia uno autoritario, si se abordan elementos como la forma de ejercer el poder.

\section{Consideraciones finales}

Son evidentes los signos de agotamiento del Sistema Político Venezolano instaurado en 1958, pero en la etapa política que abarca desde 1999 hasta el 2020, no se han revertido las condiciones generadoras de la crisis política ni dentro del sistema político propiamente dicho, ni en otros sistemas como el económico y el social con el cual se interactúa. Por el contrario, en el período analizado se observa un deterioro de las instituciones políticas debido a la desinstitucionalización que genera el proceso "revolucionario" adelantado por el gobierno de Hugo Chávez y radicalizado por Nicolás Maduro. A pesar de las promesas de cambios estructurales, aún persisten prácticas políticas del pasado, esta vez exacerbadas. Son el caso del clientelismo, el reparto de los ingresos petroleros como medio para lograr apoyos al proceso, un fuerte centralismo conjugado esta vez con personalismo y las prácticas corruptas en el manejo de los bienes de la nación.

Un hecho que destaca desde la gestión de Chávez es que se utilizaron medidas legales, reglamen $\neg$ tarias, e informales, dirigidas a restringir la libertad de expresión y asociación, obstruyendo el surgimiento del pluralismo democrático; paralelamente, se alternaron con medidas represivas. En la etapa post-Chávez se ha exacerbado su uso. Nicolás Maduro ha puesto todo su interés en la supervivencia del régimen con

12. Según el Programa Venezolano de Educación-Acción en Derechos Humanos (2021), desde 2013 hasta diciembre de 2020 fueron asesinadas 76 personas mediante tortura y 36.842 sufrieron tratos crueles e inhumanos. Estos casos documentados forman parte del expediente que se sigue a Nicolás Maduro y su cadena de mando en la Corte Penal Internacional por crímenes de lesa humanidad. 
el fin de mantener el poder asfixiando cualquier salida de diálogo, la negociación y consenso, que son los mecanismos indispensables para dirimir los conflictos dentro de una democracia.

Se observa la inexistencia de una alternativa frente a las tensiones presentes y no se advierte ningún tipo de negociación concreta formulada con el ánimo de avanzar en un proceso de reconciliación nacional capaz de superar la fuerte polarización política, social e ideológica existente. Si bien con Chávez la mayor tensión estuvo relacionada con la habilidad mostrada por el mandatario para introducir y poner a funcionar un nuevo modelo socialista, sin violar normas democráticas básicas, aunque utilizando con discrecionalidad la potestad del Estado para normary controlar cualquier proceso deliberativo contrario a la ideología socialista que el gobierno profesaba, Maduro ha avanzado en la consolidación de un Estado cerrado y excluyente, que no da cabida a ningún tipo de reducto opositor. $\mathrm{Su}$ talante autoritario se apoya en la legalidad construida conforme a su proyecto político y por ello no tardó en remodelar la estructura legal y las relaciones de poder en el país; asimismo, se ha blindado electoralmente para seguir apostando a una legitimidad democrática en su gobierno, pese a no ser reconocido por la comunidad internacional democrática.

El desplazamiento hacia el autoritarismo ha sido un proceso gradual, tanto Chávez como Maduro actuaron desde adentro de la democracia, controlándola, reformándola, buscando su sustitución con otro tipo de instituciones, o dándole un nuevo funcionamiento a las instituciones democráticas acorde con los fines del proyecto socialista. Ambos mandatarios desarrollaron elementos totalitarios de tipo político, en el control absoluto de las instituciones públicas y privadas, y en el control social de la población mediante mecanismos organizativos verticales y reivindicativos, con los cuales se abarca buena parte de la vida humana, que hoy día llega a las actividades básicas de los individuos, como lo son: comer, curarse, protegerse y desplazarse. La ausencia de un liderazgo carismático en Maduro precipitó la consumación del proyecto político de Chávez en su vertiente autoritaria, ya que el socialismo bolivariano ha sido esencialmente un régimen personalista que está minando hasta un punto crítico al sistema político, que aun cuando pretende seguir guardando una apariencia democrática, no puede ocultar que su poder se sostiene en fraudulentas elecciones y en instituciones corruptas que son complacientes en que cada vez se otorguen más poderes al Ejecutivo.

En definitiva, de acuerdo con Easton, el Sistema Político Venezolano ha logrado persistir al utilizar recursos y acumular capacidades institucionales para tomar decisiones políticas, ejecutarlas y lograr imponerlas como obligatorias para la sociedad, enfrentando de esta manera los cambios y tensiones ocasionados por el proyecto revolucionario y socialista impulsado desde 1999. Sin embargo, tal como se ha expuesto en este trabajo, durante los gobiernos del expresidente Chávez y de Nicolás Maduro, las condiciones mínimas del juego democrático se han minado por las evidentes prácticas autoritarias, creando un clima tanto inestable como peligroso que está desplazando al sistema hacia algo distinto.

Aunque la teoría de los sistemas de Easton no se centra en los factores empíricos para poder identificar el grado de tensión y posible amenaza de destrucción de un sistema, abordar el caso venezolano desde esta perspectiva teórica ha permitido establecer que tales factores son importantes para avanzar en la comprensión del tema. Resulta interesante observar cómo en poco más de dos décadas, en Venezuela se fueron consolidando instituciones autoritarias que mantienen al sistema político en un punto crítico, ya que si bien esta institucionalidad ha valido para que las autoridades gubernamentales adopten decisiones políticas y las impongan al resto de la sociedad, también ha generado un rechazo por gran parte de la población que desconoce al gobierno y sus instituciones. En tal sentido, el sistema se encuentra en una línea borrosa entre democracia y autoritarismo con formas novedosas de prácticas autoritarias para imponer las decisiones, que coexisten con fachadas electorales que buscan preservar la legitimidad de las autoridades gobernantes.

\section{Referencias}

AlbaCiudad. (2017). Presidente Maduro ordena activación del Plan Zamora tras denunciar inicio de un golpe de Estado. https://albaciudad.org/2017/04/ maduro-ordena-activar-plan-zamora-tras-denunciarque-el-departamento-de-estado-dio-luz-verde-a-ungolpe-de-estado/ [Consulta: 2020, febrero, 11]. 
Asamblea Nacional. (2021). Informe Especial sobre la situación de los parlamentarios venezolanos. Período legislativo 2016-2021. http://www.asambleanacional.gob.ve//storage/documentos/documentos/ documentos_1565797801.pdf [Consulta: 2021, noviembre, 2].

Aponte, C. y Gómez, L. (2009). El régimen político en la Venezuela actual. Caracas: Ildis/Convite.

Arenas, N. (2016). Nicolás Maduro: ¿populismo sin carisma? Cuadernos del CENDES, 33(92), 113-128.

Arendt, H. (2004). Los origenes del totalitarismo. México: Taurus.

Brewer-Carías, A. (1998). Problemas del Estado de partidos. Caracas: Editorial Jurídica Venezolana.

Brewer-Carías, A. (2005). Lecciones de la crisis politica de la democracia venezolana (Mimeo). Mesa Redonda sobre Lecciones de la Crisis Política Venezolana, Instituto de Investigaciones Jurídicas, Universidad Nacional Autónoma de México (UNAM), Ciudad de México.

Corrales, J. (2015). El legalismo autocrático en Venezuela. Cuadernos de Pensamiento Político, 47, julio septiembre, 69-82.

Chávez, H. (1999). Ideas fundamentales para la Nueva Constitución Bolivariana de la V República. Parte I - II. Ministerio de la Secretaría de la Presidencia de la República. Caracas.

Easton, D. (1999). Esquema para el análisis politico (8a ed.). Argentina: Editorial Amorrortu.

Gaitán, A. (2010). Las regresiones políticas del siglo XXI. Metapolitica, 71, 45-49.

Hanes de Acevedo, R. (1988). El clientelismo en el modelo político venezolano: un análisis preliminar. Secuencia, 10, 100-111. https://doi.org/10.18234/ secuencia.v0i10.206

Hernández, T. (2005). Venezuela 1989-2005: La polarización política como conflicto cultural ¿De la partidocracia al neoautoritarismo popular? Comunicación:, 132, 89-101.

Instituto Latinoamericano de Investigaciones Sociales. (2010). Antecedente a la representación propor cional en el sistema electoral venezolano. Caracas: Fundación Foro Socialdemócrata.

Kornblith, M. (1996). Crisis y transformación del sistema político venezolano: nuevas y viejas reglas de juego. En Álvarez, A. (Ed), El sistema político venezolano: Crisis y transformaciones (pp. 1-31). Caracas, Venezuela: IEP-UCV.

Kornblith, M. (1998). Venezuela en los 90. Las crisis de la democracia. Caracas: Ediciones IESA.

Levine, D. (1994). Goodbye to Venezuelan Exceptionalism. Journal of Interamerican Studies and World Affairs, 36(4), 145-182. https://doi. org/10.2307/166321
Lissidini, A. (2008). La democracia directa en Venezuela: ¿Democracia participativa o democracia plebiscitaria? C2d Working Paper Series, 25. Centre for Democracy Studies Aarau (ZDA) at the University of Zurich.

López Maya, M. et al. (1989). De Punto Fijo al Pacto Social. Desarrollo y Hegemonía en Venezuela (19581985). Caracas: Fondo Editorial Acta Científica Venezolana.

López Maya, M. (2010). Notas sobre la polarización política en Venezuela y la región. Seminario Participación y respuestas de movimientos y organizaciones sociales a los cambios políticos en Bolivia, Ecuador y Venezuela. Caracas.

Marsh, D. y Stoker, G. (2010). Theory and Methods in Political Science. London: MacMillan. https://doi. org/10.1007/978-0-230-36664-0

Martínez, M. (2008). Golpes de estado en Venezuela durante el período 1989-2004: Evolución del conflicto y proceso sociopolítico. Análisis Político, 64, 3-21.

Molina, J. (2001). El sistema de partidos venezolano: de la partidocracia al personalismo y la inestabilidad. La desinstitucionalización y sus consecuencias (Mimeo). Caracas.

Norden, D. (2008). ¿Autoridad civil sin dominación civil? Las relaciones político-militares en la Venezuela de Chávez. Nueva Sociedad, 213, 170-187.

Observatorio Venezolano de Conflictividad Social. (2014). Conflictividad social en Venezuela en 2014. http://observatoriodeconflictos.org.ve [Consulta: 2021, marzo, 18]

Observatorio Venezolano de Conflictividad Social. (2017). Conflictividad social en Venezuela en 2017. http://observatoriodeconflictos.org.ve [Consulta: 2021, marzo, 18]

Programa Venezolano de Educación-Acción en Derechos Humanos. (2018). Resumen de Informe Anual. Situación de los Derechos Humanos en Venezuela. Provea. Caracas.

Programa Venezolano de Educación-Acción en Derechos Humanos. (2021). Día Internacional Víctimas de Torturas. https://twitter.com/_Provea/status/1408900391081816065 [Consulta: 2021, mayo, 14].

Ramos, A. (2011). La "revolución" que no fue. Desgobierno y autoritarismo en la Venezuela de Chávez. Estudios Políticos, 38, 69-91.

Rey, J. (1991). La democracia venezolana y la crisis del sistema populista de conciliación. Revista de Estudios Políticos, 74, 533-578.

Rivas, J. (2012). La experiencia populista y militarista en la Venezuela contemporánea. Working Papers 307, Barcelona: Institut de Ciències Polítiques i Socials, 3-32.

Sánchez, J. (2009). Presente y futuro del sistema de partidos en Venezuela. Provincia, 22, 89-105. 
Revista de Artes y Humanidades UNICA. (2005). Pacto de 'Punto Fijo'. Revista de Artes y Humanidades UNICA, 13, 237-246.

Tell, G. (2014). Venezuela: de las protestas a la coyuntura electoral. Diálogo Político, 31(2), 8-15.

Velasco, A. (2017). Chavismo en crisis, chavismo en disputa. Nueva Sociedad, 271, 4-12.

Vera, L. (2005). Liderazgo Politico, Renta y Politica Económica: La gestión económica en la era de Chávez. (Mimeo). Caracas. 